\title{
Analysis on the Influence of Tencent's Business Model Innovation on Business performance
}

\author{
Kailun Fu \\ 2001 Longxiang Blvd., Longgang District, Shenzhen \\ angela@cas-harbour.org
}

Keywords: Internet enterprises; Business model; Business performance.

\begin{abstract}
This paper takes Internet enterprise Tencent as the research target, the purpose of which is to explore the relationship between business model innovation and business performance, and to provide concrete and feasible guidance and suggestions for enterprises in reality with specific cases. In this paper, the typical enterprises are taken as the analysis object and the path of business model innovation affecting the business performance of enterprises is obtained by logical reasoning method. Business model innovation affects the path of business performance. Therefore, the influence of business model innovation on business performance of Internet enterprises is analyzed and the advantages of economic value added in measuring business performance are discussed. By using normative research methods, mathematical model and statics are analyzed by combination of common characteristics of enterprises in the field of the Internet. This paper found that there was a synchronous relationship among business model innovation and business performance. In other words, the innovation of business model has positive impact on a firm's business performance.
\end{abstract}

\section{Introduction}

Like IT innovation, which calls for using technology in new ways to create a more efficient and agile organization, business innovation should enable the achievement of goals across the entire organization, with sights set on accomplishing core business aims and initiatives. And in modern society, business controls the fortune of a company. Therefore, it is beneficial for a company to do the business innovation. However, the relationship between the business innovation and companies' performance is ambiguous.

After decades of development, the Internet has become an indispensable part of people's life and social economy. Internet technology continues to affect people's way of thinking, as well as the mode and efficiency of economic operation. Internet enterprises lead the rapid growth trend in their areas. Behind those enterprises' success, a couple of instructions for later entry firms' healthy growth can be analyzed. This article takes Tencent as research object, mainly illustrating the significance of business model innovation in a company's business performance. Moreover, a model intended to research the relationship between business model innovation and business performance has been set up.

\section{Overview of Tencent Company}

Tencent was founded in 1998. After years of development, Tencent provides its users with "one-stop online life service" as the ultimate goal, from the initial QQ client to the later QQ client [1]. With the development of social network, network media and other services, the core and the product system of the whole ecosystem have been almost realized in desktop, Web terminal and mobile terminal. In addition, Tencent has absolutely dominant market share in portals, social platforms and other fields.

Tencent has stepped into the growth strategy of every business and built itself into a representative enterprise with full Internet coverage. Therefore, Tencent is an irreplaceable research object for internet-related issues, especially in business models. Tencent's business model is typical in the field of Internet and provides a multi-service classification research object. 
In short, this paper chooses Tencent as a case study of business model innovation. Undeniably speaking, Tencent is widely involved in communications, portals, broadcasting, network security and other Internet services. In order to become the Internet enterprise with the most business types in the Internet industry, Tencent has implemented its development strategy in many markets. In addition, Tencent is listed in Hong Kong as the research object and the company's operational information is open and reliable [1]. What's more, its performance is very good, and its inn is also very good. The ability to applaud makes the conclusion persuasive.

\section{Case study and analysis on Tencent's business model innovation}

\subsection{Innovative customer value}

When looking for a new long tail, network enterprises need to pay attention to users' needs that cannot be met due to distance, time, transaction costs and other realistic factors. Through linking partners, enterprises establish network service platforms, realize the full flow of information and form an effective docking between user demand and market supply. Tencent released the White Paper of China Internet Open Platform in 2012. According to the white paper, non-game applications on Tencent's open platform are growing rapidly. Among them, simple and easy-to-use tool applications are especially popular with the users. Tencent is digging out huge demand from seemingly insipid segments.

Tencent' s success in innovating customer value shows that apps that seem to satisfy simple needs can bring huge market opportunities to enterprises [2]. Although the company concentrates on a limited area, it may still succeed and make full use of the so-called "long tail effect". On Tencent Open Platform, user demand replaces product function and guides application design and development of software.

\subsection{Analysis on Tencent's business model innovation}

When an Internet enterprise innovates its own business model, it should excavate the changing customer needs and determine the development direction of the enterprise according to external environment and internal operation process of the enterprise. Tencent accurately segmented target into 5 aspects.

(1) Critical operations

Tencent focuses on six major businesses, including social networking, online media, interactive entertainment, mobile internet, e-commerce and advertising, and strengthens its platform strategy.

(2) Important cooperation

In the mobile field, Tencent and China Unicom cooperate to develop a variety of wireless Internet value-added services. In June 2001, Tencent and Unicom launched EMB, a new mobile life service. In August of the same year, Tencent and Mobile launched "Mobile QQ" service which was a Tencent instant messaging system and mobile operation platform. Three times in cooperation with mobile operators, Tencent fully meet the communication demand between Internet users and mobs by taking advantage of its own strengths and the network effects of the existing mobile platforms[3].

(3) Channel access

In June 2011, Tencent launched QQ, Tencent Friends, Qzone and Tencent Weibo open platforms. Tencent has powerful channels to contact customers through multi-platform open strategic innovation, such as simultaneous development of game developers and multi-platform release, which could greatly improve the relationship between games and users. Small and medium-sized network operators can also register once and publish their products to multiple open platforms [4].

(4) Core resources

The Instant messaging platform is one of Tencent's core resources. The competitiveness of platform includes real-time information capability and direct contact capability. The former greatly improves the discovery ability of application products on the platform and enables users to form a rapid understanding of new products, while the latter makes application products become better and better in the rolling and iteration process. The interaction between the two organizations enables 
Tencent to rapidly develop new products and improve product quality after discovering new needs of users. The two-way communication ability of this kind of information has become one of Tencent's core competitiveness.

(5) Customer relations

In maintaining a good "enterprise-customer" relationship, Tencent has always agreed with the corporate purpose of "satisfying the needs of users as the primary goal" and provided satisfactory services. To maximize the protection of customer interests of products or services, analysis of changes in market user needs, timely feedback of user opinions on products and PRO are needed. More customer service content than expected will be achieved by enhancing users' satisfaction and dependence on products, locking in users' use of products as much as possible and maximizing business performance with users[2]. Satisfaction, continuous communication and cooperation with customers, employees, owners, partners and other stakeholders would achieve mutual benefit and win-win situation.

\section{The mechanism of business model innovation on business performance}

\subsection{Theoretical Model of business model innovation affecting business performance}

On the basis of reviewing the relevant literature of business model and its innovation path, it is concluded that business model consists of several elements, namely customer segmentation, value proposition and K. The impact of Ernst \&amp includes Young's business, key partners, distribution channels, core resources, capabilities, customer relationship, cost structure, revenue sources and business model innovation on business performance of enterprises. These factors will have impacts on the business performance of enterprises, but some factors are not direct nor easy to quantify and a single factor cannot reflect all. From the perspective of innovation, this paper takes business model as the key element. Education is divided into different stages of innovation.

Among them, the primary stage is customer value innovation. Considering two aspects, one is to open up new markets and to find new target customers, the other is to re-position customer need[4], the listed market can be satisfied. Therefore, the focus of customer value innovation is the target customer and value proposition. Margaret stressed that the next stage is to establish customer value creation system. The system is based on new target customers or value propositions and focuses on how to meet customers' needs[4] as well as concentrating on key business, important cooperation, channels, core resources and customer relationships.

The last stage is to realize the economic benefits of enterprises themselves. Through the establishment of customer value creation system, network enterprises achieve the goal of customer value creation. In addition, enterprises need to consider their own growth, and the basic driving force for the sustainable development of enterprises is their profit level.

The business model elements involved in these three phases are not isolated but interacted with each other. An enterprise should not only define which customers the enterprise wants to serve, but also what they can bring to customer. In the initial stage, feasibility that enterprises integrate their own and external resources according to unsatisfactory conditions to produce marketable products or services is considerable. Enterprise should attract more users to join the value network created by the products, forming a 'huge user base to create traffic, partial payment'. User mechanism supports enterprise's development and growth. Only when the foundation of the primary stage of innovation written above is laid, can the innovation of each element be realized. In other words, realizing the economic interests of the enterprise itself improves the business performance of the enterprise. The design of enterprise value acquisition mechanism directly affects the business performance of enterprises[5]. Only a reasonable 'cost-benefit structure' can improve the growth of enterprise value.

Therefore, this paper argues that there is a certain order of innovation behavior, business model innovation will ultimately have an impact on the operating performance of Internet enterprises. Enterprise performance through the last stage of innovation behavior (See 4.1) is mainly represented by the rational design of cost structure and income sources. In the study of the impact of business 
model innovation, this paper starts from the operating performance of network enterprises, and analyzes the innovation path of enterprises from the perspective of business model elements.

\subsection{Selection of business performance evaluation indexes}

There are three types of evaluation indexes of enterprise management performance, which are financial index, non-financial index, comprehensive use of financial index and non-financial index.

\subsubsection{Evaluation of financial indicators}

In this stage, the operating performance evaluation indexes applied to enterprises include pre-tax profit, net profit, return on investment and so on. With the continuous growth of enterprises, the pursuit of operation is no longer limited to the maximization of profits, but is transformed into the maximization of owners' rights and interests, resulting in great defects in this way of evaluation. First, referring to the general accounting standards, the cost of all investment funds is not involved in measuring the profitability of enterprises, but only the cost of borrowing funds is eliminated, which cannot truly reflect the profits of enterprises. Second, the reference accrual basis and the diversity of financial evaluation indicators lead to the enterprise annual report which cannot maintain the consistency all the time, causing the calculated results cannot truly reflect the operating results of the enterprise. Third, there are a large number of behaviors that affect the profit of the enterprise in reality, which can only be described quantitatively. Fourth, in some cases, there is artificially hard intervention.

\subsubsection{Evaluation of non-financial indicators}

In this stage, the common non-financial indicators are customer satisfaction, product and service quality, enterprise strategic objectives, enterprise development potential and so on. Different from financial indicators, enterprises that use non-financial indicators to evaluate business performance feel that firstly, non-financial indicators to a large extent reflect the future development strategy of enterprises. The non-financial index contains a certain degree of qualitative analysis, describing the information of consumers, employees, shareholders and other stakeholders, including core resources, talent reserves and other information related to the long-term development strategy of the enterprise; second, the non-financial index reflects the creativity, management level, cooperation ability and other information of the enterprise, the above information can fully predict whether the enterprise can obtain profits; third, non-financial indicators can comprehensively predict the future operating performance of enterprises.

The shortcomings of non-financial indicators are as follows. First, enterprises need to invest more time and resources in the evaluation of non-financial indicators. Second, non-financial indicators use qualitative and quantitative means to evaluate the business performance of enterprises, the diversification of evaluation methods will cause difficulties to the integration of the final relevant indicators. Third, there is no reliable method to verify the exact impact of non-financial indicators on the performance of enterprises. Fourth, when sorting out the non-financial indicators, most of the index data come from questionnaires, interviews and other channels, and the data obtained through these channels cannot prove its accuracy.

\subsubsection{Evaluation of the combination of financial indicators and non-financial indicators}

Through the above analysis, this paper holds that the reasonable operating performance evaluation index should synthesize the advantages of financial index and non-financial index, and use EVA index to evaluate the operating performance of an enterprise, which has the following characteristics. First, EVA index can accurately and comprehensively reflect the operating results of an enterprise. Second, EVA index subtracts the opportunity cost of all investment funds (including owner's rights and interests and creditors' debt), and takes effective means to control the income that enterprises can obtain and the risks they must bear, so as to integrate relevant factors to maximize shareholder value. Third, all business strategies of enterprises are explained alone through EVA indicators, so that enterprises can make their own goals clear. In order to accelerate the information flow of enterprises, we are committed to put forward a method on how to increase the Eva value through reasonable management. Through the analysis, this paper holds that EVA, as an index to evaluate the operating performance of an enterprise, is both accurate and comprehensive, and all the factors are taken into 
account in the operation, which makes the EVA index reflect the operational effect and operating performance of the enterprise to the greatest extent, and reflects the combination of the EVA index and the advantages of the financial index and the non-financial index.

\subsection{Business performance evaluation based on EVA index}

In 2003, the State-owned Assets Commission disclosed the Interim Measures for the Performance Assessment of the Head of the Central Business, and the total profit and the return on net assets as the performance evaluation index; in 2017, the method was changed, and the total profit and the EVA index were continued to be used as the operating performance evaluation index to improve the proportion of EVA index in the evaluation index system. The multiple changes of the state-owned assets committee to the business performance evaluation index system of the relevant enterprises have enhanced the importance of the EVA index, indicating that the state-owned assets committee has developed its business performance evaluation of the related enterprises from the pursuit of profit maximization in the past to the appreciation of the value of the enterprises themselves.

In the interim measures for the Evaluation of the operating performance of the responsible Persons of Central Enterprises, the State-owned assets Committee has given a concrete method for calculating the EVA index. Taking the relevant enterprises as an example, the EVA index describes the net operating profit of the company after deducting income tax, minus the total cost of capital invested by the enterprise, and the remaining value. The specific calculation process is as follows: EVA index = net operating profit after income tax-all input cost $=$ net operating profit after deducting income tax-adjusted capital * average capital cost ratio, of which the Net operating profit after deducting income tax $=$ net profit (adjusted R \& D expenditure after interest expenditure $* 50 \%) *(1 \leq 25 \%)$;

Adjusted capital = average value of owner's equity, average value of creditor's equity, average value of current liability after deducting interest, average value of ongoing construction project expenditure, and: average value of owner's equity = (owner's equity at the end of the year of the beginning of the year) $/ 2$, average value of creditor's equity $=$ (creditor's equity at the end of the year of the beginning of the year) $/ 2$, Average current liability after interest deduction $=$ (current liability at the end of the year) $/ 2$, average expenditure on construction projects under way $=$ (expenditure on projects in progress at the end of the year of expenditure under construction at the beginning of the year) / 2 .

The capital cost ratio is $5.5 \%$ in most enterprises. For large state-owned enterprises, the assets of this kind of enterprises are huge and the realization is difficult. In the process of development, the capital cost ratio is mainly engaged in business related to the national strategy, and the value of capital cost ratio is lower than the general level. For enterprises mainly engaged in industrial projects, if their asset-liability ratio is higher than $75 \%$, or if the asset-liability ratio of enterprises that are mainly engaged in industrial projects is higher than $80 \%$, then the value of capital cost ratio of such enterprises is higher than the general level. Once an enterprise uses a certain capital cost ratio, the value is maintained for three years.

Table 1. The table of EVA calculation of Tencent in 2009-2018

\begin{tabular}{cccc}
\hline Year & $\begin{array}{c}\text { After-tax operating profit } \\
\text { (millions) }\end{array}$ & $\begin{array}{c}\text { Cost of capital } \\
\text { (millions) }\end{array}$ & $\begin{array}{c}\text { Economic value } \\
\text { added (millions) }\end{array}$ \\
\hline 2018 & 18376 & 3565 & 14811 \\
\hline 2017 & 13619 & 2711 & 10908 \\
\hline 2016 & 8957 & 1957 & 7000 \\
\hline 2015 & 9936 & 1121 & 8815 \\
\hline 2014 & 5222 & 548 & 4674 \\
\hline 2013 & 2816 & 339 & 2477 \\
\hline 2012 & 1568 & 254 & 8314 \\
\hline 2011 & 1064 & 185 & 332 \\
\hline 2010 & 485 & 153 & 355 \\
\hline 2009 & 441 & 86 & 379 \\
\hline
\end{tabular}

Here, this paper analyzes the operating performance of Internet enterprises based on EVA indicators. According to Tencent's 2009-2018 report data, the EVA index of the company is 
calculated (see table 1) and the value of net operating profit after deducting income tax is directly extracted from Tencent's annual report data for previous years, and all input capital costs can be calculated by the equation, capital costs = (average owner's equity, average creditor's equity, average current liability after interest and average of ongoing construction project expenditure) $\mathrm{x}$ average capital cost ratio, which calculates the average value of the owner's equity, the average value of the creditor's equity, the average value of the current liability after deducting interest, and the expenditure being incurred on the construction project. The data needed for the average can also be extracted directly from Tencent's annual reports over the years, and the average capital cost ratio is $5.5 \%$.

According to the annual EVA data, in the process of Tencent's growth, with the continuous innovation of business model, EVA growth rate is rapid, and the change of business model is synchronous. Among them, innovation leads to the expansion of revenue sources. With the increase of Tencent users, the marginal cost of producing products or services continues to decrease, or even tends to zero, so that the net operating profit of enterprises increases rapidly year by year, and quickly exceeds the performance of net operating profit of enterprises when the previous profit model is single or even unknown.

\section{Conclusion}

The focus of this paper is the impact of business model innovation on the business performance of Internet enterprises. Based on Tencent's successful case, a couple of mandatory key elements to set up business model innovation haven been pointed out.

Hence, there is a potential research assumption, whether an enterprise choosing innovate on its business model will conduce to its business performance. After referring and summing up related literature, a model aims at analyzing the relationship between business model innovation and business performance has been established. Throughout the whole analysis model, the statistic shows that there's a synchronous relationship among business model innovation and business performance. In other words, the innovation of business model has positive impact on a firm's business performance. Lastly but importantly, are there any other stakeholders of business model's innovation having impact (positive or negative) on a firm's business performance? We are looking forward to scholars' contribution.

\section{Acknowledgement}

First and foremost, I would like to show my deepest gratitude to my teachers and professors in my university, who have provided me with valuable guidance in every stage of the writing of this thesis. Further, I would like to thank all my friends and roommates for their encouragement and support. Without all their enlightening instruction and impressive kindness, I could not have completed my thesis.

\section{References}

[1] Y. Wu, Case Studies: Supply Chain A[M]. Springer International Publishing, 2018.

[2] D. Seybold, C. B. Hauser, G. Eisenhart, S. Volpert, J. Domaschka, The Impact of the Storage Tier: A Baseline Performance Analysis of Containerized DBMS[M]. Springer International Publishing, 2018.

[3] T. Ndjountche, CMOS Analog Integrated Circuits[M]. CRC Press, 2017.

[4] M. A. S. Hagan, A. Donkoh, D. Awunyo-Vitor. Growth performance and economic evaluation of broiler Chicken fed with rain tree (Samanea saman ) seed meal[J]. Cogent Food \&amp; Agriculture, vol. 2, 2016. 
[5] Y. C. Ho, W. B. Wang, W. L. Shieh, An empirical study of green management and performance in Taiwanese electronics firms[J]. Cogent Business \&amp; Management, vol. 3, 2018. 